\section{THU0567 TESTING PERFORMANCE MEASURES IDENTIFIES GAPS IN JUVENILE IDIOPATHIC ARTHRITIS (JIA) CARE}

C. Barber ${ }^{1}$, D. Lacaille ${ }^{2}$, L. Lix ${ }^{3}$, K. Kroeker ${ }^{3}$, D.A. Marshall ${ }^{1}$, N. Shiff ${ }^{4}{ }^{1}$ University of Calgary, Calgary; ${ }^{2}$ University of British Columbia, Vancouver, ${ }^{3}$ University of Manitboa, Winnipeg, Canada; ${ }^{4}$ University of Florida, Gainesville, USA

Background: JIA is the most prevalent type of childhood inflammatory arthritis Timely diagnosis, treatment and ongoing care by a paediatric rheumatologist are associated with improved outcomes.

Objectives: To test the Arthritis Alliance of Canada's JIA Performance Measures: i) The percentage of patients with new onset JIA with at least one visit to a paediatric rheumatologist in the first year of diagnosis; ii) The percentage of patients with JIA under rheumatology care seen in follow-up by a paediatric rheumatologist at least once per year.

Methods: Validated JIA case ascertainment algorithms were used to identify cases from provincial health administrative databases in Manitoba, Canada in patients $<16$ years of age with $\geq 6$ months of health insurance coverage in the population registry between 01/04/2005 and 31/03/2015. Cases were identified by either 1 hospitalisation separation with an International Classification of Disease (ICD)-10 code for JIA (M05.X, M06.X, M08.X, M45.X) or $\geq 2$ physician billing claims (ICD-9 codes: $714 . x$ or $720 . x$ ) for $J I A \geq 8$ weeks apart within 2 years. $A$ 3 year washout period prior to the first code was used to determine the percentage of incident JIA patients with $\geq 1$ visit to a paediatric rheumatologist in the first year. For reporting the percentage of JIA patients seen in yearly follow-up, once a patient is seen at least twice by a paediatric rheumatologist they are considered under rheumatology care. The measure was computed by comparing yearly observed and expected follow-ups. The proportion of patients with gaps in care of $>12$ and $>14$ months between consecutive rheumatologist visits was also calculated. As there is no paediatric rheumatologist identifier in Manitoba administrative datasets, a physician was identified as a paediatric rheumatologist if they had $>40$ visits for individuals $\leq 16$ years in a year and at least $50 \%$ of those visits in a year were JIA. This identified 5 physicians.

Results: 194 incident cases of JIA were diagnosed between 01/04/2008 and 03/ 31/2015. The median age at diagnosis was 9.1 years (Q1 5.5, Q3 12.8) and $71 \%$ were female. Table 1 describes the number of JIA cases who saw a paediatric rheumatologist within a year of diagnosis (between $51 \%$ and $81 \%$ ). Table 2 describes the percentage of patients seen on a yearly basis with no significant changes seen over time $(p=0.47)$. A single gap of $>12$ months was seen in $52 \%$ $(n=144)$ and $\geq 2$ gaps of $>12$ months were seen in $11 \%(n=28)$. One gap of $>14$ months was seen in $34 \%$ of cases, and only $5 \%$ had $\geq 2$ gaps $>14$ months.

Abstract THU0567 - Table 1. Number of incident JIA cases that have seen a paediatric rheumatologist within the first year

\begin{tabular}{lcc}
\hline $\begin{array}{l}\text { Fiscal Years } \\
\text { (Some year combined due to } \\
\text { small sample sizes, } \mathbf{n}<5 \text { ) }\end{array}$ & $\begin{array}{c}\text { Number of } \\
\text { incident JIA } \\
\text { cases }\end{array}$ & $\begin{array}{c}\text { Percentage seen by a paediatric } \\
\text { rheumatologist within a year }\end{array}$ \\
\hline $2008 / 2010$ & 50 & $80 \%$ \\
$2010 / 2012$ & 54 & $81 \%$ \\
$2012 / 2014$ & 55 & $78 \%$ \\
$2014 / 2015$ & 35 & $51 \%$ \\
\hline
\end{tabular}

Abstract THU0567 - Table 2. Proportion of JIA follow-up visits by a paediatric rheumatologist using fixed 12-month intervals

\begin{tabular}{lccccccc}
\hline & $\mathbf{2 0 0 8 /}$ & $\mathbf{2 0 0 9 /}$ & $\mathbf{2 0 1 0 /}$ & $\mathbf{2 0 1 1 /}$ & $\mathbf{2 0 1 2 /}$ & $\mathbf{2 0 1 3 /}$ & $\mathbf{2 0 1 4 /}$ \\
& $\mathbf{0 9}$ & $\mathbf{1 0}$ & $\mathbf{1 1}$ & $\mathbf{1 2}$ & $\mathbf{1 3}$ & $\mathbf{1 4}$ & $\mathbf{1 5}$ \\
\hline Observed & 74 & 94 & 82 & 72 & 70 & 66 & 68 \\
Expected & 101 & 120 & 114 & 116 & 123 & 116 & 118 \\
Percent & 73 & 78 & 72 & 62 & 57 & 57 & 58 \\
\hline
\end{tabular}

Conclusions: Many JIA patients are not seen by a paediatric rheumatologist within a year of diagnosis, and up to half of those followed have at least $1 \mathrm{gap}$ in care of $>12$ months. Such gaps may lead to a delay in diagnosis, timely treatment and ongoing care that could impact outcomes.

Disclosure of Interest: None declared

DOI: 10.1136/annrheumdis-2018-eular.3380

\section{THU0568 \\ BIOSIMILAR USE IN PATIENTS WITH JUVENILE IDIOPATHIC ARTHRITIS IN A REAL-WORLD SETTING IN THE UNITED KINGDOM}

D. De Cock ${ }^{1}$, L. Kearsley-Fleet ${ }^{1}$, R. Davies ${ }^{1}$, E. Baildam² ${ }^{2}$ M. Beresford ${ }^{2}$,

H. Foster ${ }^{3}$, T. Southwood ${ }^{4}$, W. Thomson ${ }^{5}$, K. Hyrich ${ }^{1,6}$, on behalf of the BCRD investigator group. ${ }^{1}$ Arthritis Research UK Centre for Epidemiology, Manchester University, Manchester, ${ }^{2}$ Clinical Academic Department of Paediatric

Rheumatology, Alder Hey Children's NHS FoundationTrust, Liverpool; ${ }^{3}$ Newcastle University, Newcastle; ${ }^{4}$ School of Immunity and Infection, Birmingham University, Birmingham; ${ }^{5}$ Arthritis Research UK Centre for Genetics and Genomics, Manchester University, ${ }^{6}$ Manchester Academic Health Science Centre, Central Manchester NHS Foundation Trust, Manchester, UK

Background: Although biosimilars are routinely used in adults with musculoskeletal diseases, there are limited data regarding the use of biosimilars in patients with juvenile idiopathic arthritis(JIA).

Objectives: To describe the characteristics of patients with JIA starting biosimilars in the United Kingdom (UK) following their approval in the UK with musculoskeletal diseases.

Methods: Patients were selected from the Biologics for Children with Rheumatic Diseases (BCRD) study, launched in 2010, an ongoing prospective UK study of biologic therapies other than the etanercept originator (followed in a separate parallel study) in JIA. Baseline information is collected via questionnaires completed by the treating physician or affiliated clinical research nurse. Follow-up data including disease activity measures and changes in drug therapy are collected at 6 months, 1 year and annually thereafter. From 30-Sept-2015, data has been captured on 3 biosimilars available in the UK: 2 infliximab and 1 etanercept biosimilar. Results: To 12-Dec-2017, 58 patients were identified in the BCRD study starting a biosimilar; $48(84 \%)$ infliximab and $10(17 \%)$ etanercept biosimilars (table 1). Of these, $36(62 \%)$ started a biosimilaras their first biologic therapy. Seventeen (29\%) switched to a biosimilar from a non-originator biologic. Five patients switched from their originator. Follow-up data ranging from 6 months to 2 years were available in 14 patients. Four patients switched to another biologic in this period, 3 switching from an infliximab biosimilar to tocilizumab, and 1 etanercept biosimilar patient to adalimumab. Two serious adverse events in a 90 day exposure window were reported, both cases of recurrent uveitis in patients on an infliximab biosimilar switching from a non-originator biologic.

Abstract THU0568 - Table 1

\begin{tabular}{|l|l|l|l|}
\hline Patients who are & $\begin{array}{l}\text { Biological } \\
\text { naive }\end{array}$ & $\begin{array}{l}\text { Switched } \\
\text { from a non- } \\
\text { originator }\end{array}$ & $\begin{array}{l}\text { Switched } \\
\text { from } \\
\text { originator }\end{array}$ \\
\hline Number & 36 & 17 & 5 \\
\hline Biosimilar & & & \\
\hline Infliximab biosimilars & $28(77 \%)$ & $17(100 \%)$ & $3(60 \%)$ \\
\hline etanercept biosimilar & $8(22 \%)$ & $0(0 \%)$ & $2(40 \%)$ \\
\hline ILAR class & & & \\
\hline Persistent Oligoarthritis & $4(11 \%)$ & $4(24 \%)$ & $0(0 \%)$ \\
\hline Extended Oligoarthritis & $8(22 \%)$ & $5(29 \%)$ & $1(20 \%)$ \\
\hline RF Negative Polyarthritis & $13(36 \%)$ & $4(24 \%)$ & $1(20 \%)$ \\
\hline RF Positive Polyarthritis & $0(0 \%)$ & $0(0 \%)$ & $0(0 \%)$ \\
\hline \multicolumn{1}{|c|}{ Psoriatic Arthritis } & $2(6 \%)$ & $3(18 \%)$ & $3(60 \%)$ \\
\hline Enthesitis Related Arthritis & $8(22 \%)$ & $1(6 \%)$ & $0(0 \%)$ \\
\hline \multicolumn{1}{|c|}{ Unknown } & $1(3 \%)$ & $0(0 \%)$ & $0(0 \%)$ \\
\hline $\begin{array}{l}\text { Active uveitis at start of } \\
\text { therapy }\end{array}$ & $4(11 \%)$ & $7(41 \%)$ & $2(40 \%)$ \\
\hline Female & $22(61 \%)$ & $12(71 \%)$ & $2(40 \%)$ \\
\hline Age (years) & $13(9-15)$ & $14(11-15)$ & $13(12-16)$ \\
\hline Disease duration (years) & $2(1-5)$ & $6(3-10)$ & $7(6-13)$ \\
\hline Active Joints (71 joints) & $2(1-4)$ & $0(0-2)$ & $0(0-0)$ \\
\hline Limited Joints (71 joints) & $2(1-4)$ & $2(0-4)$ & $0(0-1)$ \\
\hline Physician Global (0-10cm) & $2(2-4)$ & $1(0-2)$ & $0(0-0)$ \\
\hline Patient Global (0-10cm) & $5(1-7)$ & $2(0-4)$ & $2(0-4)$ \\
\hline Pain VAS (0-10cm) & $4(1-7)$ & $4(2-5)$ & $1(0-1)$ \\
\hline CHAQ (0-3) & $1(0-1)$ & $0(0-2)$ & $0(0-1)$ \\
\hline $\begin{array}{l}\text { All data presented are number (percentages) or median (interquartile range). International League of } \\
\text { Associations for Rheumatology (IIAR), Rheumatoid Factor (RF), Visual Analog Scale (VAS), Childhood } \\
\text { Health Assessment Questionnaire (CHAQ), }\end{array}$ & & \\
\hline
\end{tabular}

Conclusions: Biosimilars in children and young people are used as both first-line and subsequent-line biologic therapy, although currently few UK children have been switched directly from an originator product. Whether a move towards switching all children receiving originator products to biosimilar products, as has been seen in rheumatoid arthritis, will occur is currently unknown but it is imperative that the safety of these treatment decisions are captured in patient registers. Disclosure of Interest: None declared DOI: 10.1136/annrheumdis-2018-eular.4477 